\title{
INCLUSIONES Y EXCLUSIONES EN EL CÓDIGODE TRABAJO DE CUBA. UN ANÁLISIS DESDE LA CIUDADANÍA
}

\author{
YASSIEL VÁZQUEZ \\ Facultad Latinoamericana de Ciencias Sociales, sede Ecuador \\ Recepción manuscrito: 4 de agosto de 2015 \\ Aceptación versión final: 30 de octubre de 2015
}

\begin{abstract}
RESUMEN Se presenta un análisis sobre la aprobación del nuevo Código de Trabajo en Cuba (2013). Este código constituye la primera ley que en ese país reconoce algunos de los derechos de lesbianas, gais, bisexuales, transgéneros e intersexuales (LGBTI). A partir del concepto de ciudadanía, se analiza cómo los discursos sexogenéricos de los diputados del Parlamento cubano influyeron en la inclusión de la orientación sexual, pero no de la identidad de género y de los portadores de viH. En conclusión, este proceso posicionó a las desigualdades en el trabajo como problema en la agenda pública del país.

palabRAS ClaVe Ciudadanía, desigualdades, trabajo, identidades sexogenéricas.
\end{abstract}

\begin{abstract}
An analysis is presented of the approval of the New Work Code in Cuba (2013). This code is the first law in this country recognizing some of the rights to lesbians, gays, bisexuals, transgender people and intersex people (LGBTI). Based on the citizenship concept, it is clear how the sex-and-gender legislators' speeches influenced the inclusion of sexual orientation, but not of the gender identity or HIV-positive people. In conclusion, this process placed the inequalities in work as a problem to be discussed in the public agenda of this country.
\end{abstract}

KEYWORDS Citizenship, inequalities, work, sex-and-gender identities.

JEL CODES J16, J83, D63.

\section{INTRODUCCIÓN}

El actual Código de Trabajo de Cuba constituye la primera ley que en este país reconoce algunos de los derechos de las poblaciones de lesbianas, gais, bisexuales, transgéneros e intersexuales (LGBTI); sigla y nomenclatura más convencional en América Latina con que se identifica frecuentemente a este colectivo; sin embargo, adviértase que éstas pueden variar en su organización o composición. En este trabajo se analiza el proceso de aprobación del nuevo código laboral cubano; de manera específica, comprender las particularidades que marcaron la construcción del artículo 2 del código sobre los principios que rigen el derecho al trabajo. En torno a este apartado, el movimiento por las diversidades sexuales y de género en la isla caribeña desarrolló una campaña para incluir las categorías orientación sexual, identidad de género 
y portar «vih» como elementos de vulnerabilidad en el trabajo — por una decisión política, escribo $^{1}$ «vih» en minúsculas ya que se ha convertido en un sustantivo común a partir de la sigla viH (Virus de Inmunodeficiencia Humana) y es un modo de quitarle el poder y la significación estigmatizadora que históricamente lo ha acompañado; caso igual que sida, que se ha lexicalizado totalmente- . Sin embargo, a pesar del activismo y la presencia estratégica en el parlamento cubano de actores claves del movimiento LGBTI, algunos de estos elementos fueron excluidos de la redacción final de la ley; actores importantes como la diputada Mariela Castro, presidenta del Centro Nacional de Educación Sexual (CENESEX), psicóloga, sexóloga, diputada al parlamento cubano en el período 2013-2018; hija del presidente Raúl Castro y de la dirigente feminista Vilma Espín.

A partir de esto se planeta la pregunta de este trabajo: ¿Cómo los discursos sexogenéricos de los diputados y las diputadas del parlamento cubano influyeron en las exclusiones e inclusiones que finalmente registró el Código de Trabajo? Para identificar las matrices de opinión de estos actores se construye la estrategia metodológica desde una perspectiva cualitativa con un método de investigación documental, la técnica de análisis del discurso y las fuentes que constituyen las grabaciones de tres sesiones plenarias del parlamento cubano en el mes de diciembre de 2013. En el proceso de discusión del Código de Trabajo este trabajo se posiciona activamente dentro del movimiento LGBTI cubano y participa en la lucha por el derecho al trabajo en condiciones igualitarias de estas poblaciones en Cuba.

Por ello, uno de los objetivos de este trabajo intenta reconstruir desde una visión personal el proceso por el cual la discriminación laboral por estatus positivo vih y por identidades sexuales y de género no normativas se posicionó como un problema de desigualdad en la agenda pública del país como parte el marco de discusión del Anteproyecto de Ley del Código de Trabajo. Este análisis se realiza a partir de pensar el concepto de ciudadanía como un marco interpretativo que permite reflexionar sobre cómo se construye ciudadanía desde el poder de manera desigual. Las nociones teóricas de ciudadanía dejan ver los límites que este concepto pone a las categorías de inclusión y exclusión en la elaboración de marcos legales.

\section{IDENTIDADES, DESIGUALDADES Y CIUDADANÍA: UNA APROXIMACIÓN TEÓRICA}

Sobre todo desde la sociología se han presentado debates teóricos importantes respecto a cómo las desigualdades sociales se estructuran y se reproducen a partir de identidades de clase, género, raza, etnicidad, sexualidad. A la larga, estas desigualdades identitarias han configurado los modos en que opera la ciudadanía, sobre todo en la creación de políticas públicas de reconocimiento y redistribución de la riqueza. Considero que para entender estos procesos sociales primero debemos comprender cómo ocurre la producción de las identidades, con énfasis en las identidades sexuales y de género de interés clave en este estudio.

En este breve marco teórico se entienden a las identidades desde un paradigma posestructuralista de tradición foucaulteana. Cuando hablo de identidades puedo señalar que son categorías construidas en procesos sociales de subordinación y resistencia. Esto se puede entender a través de la propuesta teórica del sociólogo jamaiquino Hall (1996), quien piensa las identidades desde los estudios culturales, detalla que la construcción de las identidades parte 
de la articulación de dos procesos fundamentales en los individuos: la sujeción y la subjetivación. Esta articulación es lo que el autor llama «sutura» como un elemento relacional que junta ambos procesos para producir las identidades. Hall (1996) asegura que:

Las identidades se construyen en el punto de encuentro de los discursos y prácticas que intentan interpelarnos, hablarnos o ponernos en nuestro lugar como sujetos sociales de discursos particulares $y$, por otro, los procesos que producen subjetividades, que nos construyen como sujetos susceptibles de decirse. (p. 20)

A partir de esa comprensión de las identidades se puede resaltar que evidentemente los resultados serán complejos y diversos en las construcciones de las identidades. Podrían justificarse así las diversas formas en las que los individuos nos construimos, combinando elementos de la interioridad y la exterioridad, articulando nociones objetivas y subjetivas. Los resultados son entonces identidades construidas, diversas, múltiples, cambiantes y variables en cada individuo a partir de la sexualidad, el género, la raza, la clase. No obstante, estas identidades se organizan de modo complejo en la sociedad a partir de ciertas normatividades, como las sexuales y de género impuestas por la norma heterosexual/cisgénero. El concepto heterosexualidad obligatoria pertenece a Rich (1999) y hace referencia a una institución política impuesta a partir de la sexualidad y el género; mientras que el término cisgénero lo utiliza Serano (2007) para describir a personas cuya identidad de género y género asignado al nacer son concordantes. En este sentido, se han legitimado unas identidades sexuales y de género superiores sobre otras y ello ha producido desigualdades sociales.

Una de las propuestas teóricas que sobresalen en los debates actuales sobre desigualdades es la del sociólogo norteamericano Tilly (2000). Este autor se presenta en el análisis sobre desigualdades como una referencia obligada en los estudios provenientes de la tradición sociológica radical y crítica a las formulaciones económicas neoclásicas. Aunque para él, todas las relaciones sociales acarrean desigualdades pasajeras, se concentra sobre aquellas que persisten, muchas veces a lo largo de la vida. Entiende que «la desigualdad humana en general consiste en la distribución dispareja de atributos entre un conjunto de unidades sociales tales como los individuos, las categorías, los grupos o las regiones» (Tilly, 200o, p. 38).

En su planteamiento teórico, Tilly (2000) asegura que las mayores desigualdades entre seres humanos son producto de las diferencias categoriales y no tanto de los atributos o competencias que poseen. En esta concepción dicotómica de la realidad se tiende a sobrevalorar una parte del par categórico mientras el otro es inferiorizado. Algunos ejemplos de estas articulaciones entre diferentes pares categóricos a partir del género y la sexualidad son las distinciones heterosexual/homosexual y cisgénero/transgénero. Estas sobrevaloraciones/inferiorizaciones no son ingenuas sino que a través de ellas se producen desigualdades mediante el acaparamiento de oportunidades. Entonces podríamos decir que los grupos heterosexuales/ cisgénero han acaparado mejor acceso a las leyes, a las nociones de la medicina, a la educación, al mercado de trabajo y, en sentido amplio, a ejercer ciudadanía plenamente.

Ser ciudadano es un privilegio otorgado desde un círculo de poder. La ciudadanía se trata de un concepto que en la actualidad se emplea de manera frecuente en los discursos políticos de los gobiernos, pero también en los movimientos sociales. La socióloga pakistaní Molyneux 
(2008) refiere que la ciudadanía tiene sus orígenes en la filosofía política liberal occidental, pero que es un concepto polivalente, pluralizado a medida que los movimientos sociales, los pluralistas legales y los teóricos democráticos han cuestionado y hasta cierto punto radicalizado su significado. Por tanto, podemos entender que en cualquier caso se trata de un término constantemente construido y repensado, que no posee un único significado. Por una parte, se ha comprendido usualmente a la ciudadanía como el hecho de conferir derechos a ciertos ciudadanos. En ese caso se identifica en la literatura esta comprensión de ciudadanía como ciudadanía pasiva y se entiende que «la ciudadanía es el fundamento legal de la inscripción como miembro social» (Molyneux, 2008, p. 28). Sin embargo, esta concepción de ciudadanía posee un carácter reduccionista porque se construye de manera unidireccional desde el Estado.

Por ello, sería interesante cuestionar esa noción de ciudadanía y ampliarla para entenderla como un escenario de disputas y luchas políticas. Eso es lo que se ha denominado como una ciudadanía activa que se construye en disputa entre el Estado y los movimientos sociales. Posee un carácter multidireccional y multidimensional toda vez que el Estado no es el único que construye ciudadanía. La autora peruana Vargas (2012) sostiene que este modo de entender la ciudadanía puede ser visto como un proceso de «descubrimiento» y construcción de nuevos derechos y como una renovada y nunca acabada construcción sociocultural. Justamente esta idea de ciudadanía activa es la que interesa destacar en este marco para pensar cómo la ciudadanía puede ser revolucionada desde el activismo.

En muchas ocasiones, cuando las personas son excluidas de la ciudadanía por sus identidades sexuales y de género no normativas, se desatan procesos de ciudadanía activa. Esto se ha pensado de manera particular en América Latina a través del concepto de ciudadanía sexual, que sería:

Aquella que enuncia, facilita, defiende y promueve el acceso de los ciudadanos al efectivo ejercicio de los derechos tanto sexuales como reproductivos y a una subjetividad política que no ha disminuido por las desigualdades basadas en características asociadas con sexo, género y capacidad reproductiva (Cabral y Viturro, 2006, p. 262).

A pesar de que la ciudadanía sexual se ha entendido más desde la óptica de lo simbólico y la discriminación, se debería ampliar esta noción para pensar tanto en desigualdades de reconocimiento como de redistribución a partir del género y la sexualidad no normativos. A través de la propuesta de la filósofa estadounidense Butler (1998), se puede explicar que la ciudadanía sexual no puede limitarse solamente a lo sexual porque las sexualidades no se reducen a lo biológico, sino que tiene implicaciones corporales. Se trataría, de acuerdo con Butler (1998), de cuerpos en relación y personas en relación que construyen dinámicas sociales, políticas y económicas a través de disputas ciudadanas.

Usualmente, a muchas personas de las poblaciones LGBTI se les niega el acceso a recursos o se les ha relegado a ciertos nichos del mercado laboral a partir de patologizar, criminalizar o inferiorizar sus diferencias sexogenéricas. Sin embargo, muchos colectivos LGBTI en América Latina, y en particular en Cuba, están reconfigurando el panorama político desde un enfoque de ciudadanía activa. En este punto se revela la importancia que tienen las regulaciones jurídicas en las discusiones sobre desigualdades y para construir ciudadanía, sobre todo porque 
ha habido en los marcos legales y en la construcción de los proyectos nacionales una predisposición hacia las identidades sexogenéricas no normativas.

Pensar las diversidades sexuales y de género en Cuba es un ejercicio de análisis que obliga a tomar en cuenta las particularidades de un contexto altamente politizado, donde ha habido una relación histórica de tensiones entre el Estado y el colectivo LGBTI cubanos. La institucionalidad en ese país pasó de castigar las identidades sexuales y de género fuera de la norma desde la década de los sesenta, a establecer atomizadas políticas públicas con carácter inclusivo a partir de la primera década del dos mil. El nuevo Código de Trabajo es uno de esos programas gubernamentales que trata de reconocer y acortar las brechas de las desigualdades entre personas heterosexuales y no heterosexuales en Cuba.

\section{EL CÓDIGO DE TRABAJO: MARCO REGULATORIO, AVANCES Y LÍMITES}

El Código de Trabajo cubano (Ley N. ${ }^{\circ}$ 116/2013) fue actualizado en diciembre de 2013 aunque la entrada en vigor ocurrió en junio de 2014. Su reajuste estuvo en correspondencia con el contexto de flexibilización de la economía cubana a partir de la aprobación de los Lineamientos de la Política Económica y Social en el vi Congreso del Partido Comunista de Cuba (2011) y de la Primera Conferencia Nacional del Partido (2012).

Esta flexibilización toma en cuenta algunas medidas de perfil económico como mayor apertura a la inversión extranjera y a la pequeña empresa privada. Sin embargo, también pudiera reconocer que el modo en que se discutió el Anteproyecto de Ley del Código de Trabajo constituyó un momento de flexibilización y de participación popular en un escenario de limitadas posibilidades democráticas. Estas posibilidades estuvieron a tono con las nuevas estrategias políticas del gobierno cubano de mostrar un período de cambio y renovación en el país. El anteproyecto de ley fue dado a conocer un año antes de que finalmente se aprobara. Como pocas veces en Cuba, una propuesta de ley fue sometida a consulta popular a través de debates en casi 70 mil asambleas sindicales a las que concurrieron más de dos millones de trabajadores y trabajadoras, según datos divulgados por el periódico Trabajadores, órgano oficial de la Central de Trabajadores de Cuba (СТC). Esta revisión llevó a modificar 101 artículos, entre otras variaciones.

Uno de los apartados transformados fue el artículo 2, el cual establece que «todo ciudadano en condiciones de trabajar tiene derecho a obtener un empleo atendiendo a las exigencias de la economía y a su elección, tanto en el sector estatal como no estatal; sin discriminación por el color de la piel, género, creencias religiosas, orientación sexual, origen territorial, discapacidad y cualquier otra distinción lesiva a la dignidad humana» (Código de Trabajo de Cuba, 2014). La propuesta desde el movimiento LGBTI cubano fue incluir la orientación sexual, la identidad de género y portar vih como factores que pueden dar lugar a desigualdades en el ámbito laboral. En investigaciones sobre realidades laborales del colectivo LGBTI se ha revelado que el mercado de trabajo no es un espacio meritocrático. Muchas de las personas con identidades sexogenéricas no normativas son segregadas a nichos específicos del mercado laboral como al trabajo sexual y al trabajo de belleza.

La socióloga española Romero (2003) revela que el ámbito del trabajo es un escenario complejo donde se construyen y se reproducen desigualdades, jerarquizaciones excluyentes 
y diferenciaciones, a partir de nociones de género, clase, raza, sexualidad, estatus migratorio, diversidad funcional, cualificación, pertenencia religiosa, edad. Si bien es cierto que la discriminación y la burla en el caso de las personas LGBTI son elementos constantes en los espacios laborales, es necesario reconocer que no solo se trata de un problema simbólico o relacional, sino de acceso real al mercado laboral o de confinamiento solo a ciertos oficios. Por ello, desde los movimientos por las diversidades sexuales y de género se ha tratado de incidir en la protección legal ante estas desigualdades, de modo que se atiendan las demandas del colectivo tanto en los aspectos de redistribución como de reconocimiento.

El texto del artículo 2 en el anteproyecto de ley, que se sometió a debate y reelaboración, no tomaba en cuenta los intereses del colectivo LGBTI en Cuba, ni mostraba un enfoque de género. Disponía que «los principios fundamentales que rigen el derecho al trabajo son: toda mujer $\mathrm{u}$ hombre en condiciones de trabajar, sin distinción de raza, color de la piel, sexo, religión, opinión política, origen nacional o social, y de cualquier otra lesiva a la dignidad humana, tiene derecho a obtener un empleo», (Anteproyecto de Ley del Código de Trabajo, 2013). A pesar de que el parlamento legisló a favor de incluir únicamente a la orientación sexual como causa de desigualdades en el trabajo, las personas transgénero y portadoras de vih quedaron desprotegidas por el Código de Trabajo y expuestas a potenciales despidos y exclusiones en los centros laborales sin protección legal. En el caso de las personas transgénero, en muchas investigaciones como en la desarrollada por la investigadora ecuatoriana Camacho (2007), se ha revelado la precariedad en la que viven muchas personas con identidades no cisgénero.

También sucede lo mismo con las personas que viven con vih. Una investigación desarrollada por un equipo de especialistas en medicina tropical en Cuba conformado por Gala, Berdasquera, Pérez, Pinto, Suárez, Fiol, Sánchez, Aragonés y Díaz (2007) refieren los problemas relacionados con las dimensiones sociales y culturales del vih. Estas dinámicas desiguales respecto a las personas consideras «sanas» (seronegativas) se concretan en el acceso a puestos laborales o el mantenimiento en el mismo cuando una persona es diagnosticada vih positiva. Por ello, tanto personas transgénero como seropositivas al vih son expuestas a la precariedad y en numerosos ejemplos terminan en estratos del mercado laboral específicos como el de la belleza o el trabajo sexual. A su vez, en estas poblaciones la incidencia del vih es catalogada de alta y ello junto a otros factores influye en que la esperanza de vida de las personas transgénero, sobre todo transfemeninas, en América Latina sea de 35 años, según un reporte de la Comisión Interamericana de Derechos Humanos (CIDH) del año 2015.

\section{EL PROBLEMA, LA CAMPAÑA Y LOS ACTORES}

¿Cómo el problema de las desigualdades en lo laboral, que afecta a las personas con identidades sexo-genéricas no normativas y estatus positivo al vih, logró posicionarse en la agenda pública de Cuba, particularmente en los debates de la Asamblea Nacional del Poder Popular? En este análisis no podría dejarse de lado el (auto)liderazgo del colectivo LGBTI asumido por el Centro Nacional de Educación Sexual (cenesex). Su presidenta, Mariela Castro, ha venido organizando el movimiento por las diversidades sexuales y de género en Cuba desde el año 2007. En este tiempo, ha encabezado varias acciones a favor de la visibilización de la población 
LGBTI, la construcción de algunas políticas públicas y la sensibilización de la sociedad cubana hacia los problemas que enfrentamos como sujetos y sujetas discriminados en varios espacios como la familia, la escuela, el trabajo, el ejército, las organizaciones políticas. De manera especial, han sobresalido en estas acciones las jornadas cubanas contra la homofobia y la transfobia, en el marco del 17 de mayo de cada año.

El CENESEX y sus jornadas constituyeron el embrión para que en varias ciudades del país se organizaran grupos de activistas, a veces de la mano de la institución rectora y otras de manera independiente, como la Fundación Arcoíris, Placetas LGBTI, Hombres por la Diversidad, Fundación Cubana por los Derechos Humanos LGBTI, entre otras. Muchos de estos activistas - de los cuales el autor de este trabajo forma parte y se identifica- pertenecen a la intelectualidad cubana y desde los medios de comunicación, el arte, la academia científica y otras esferas profesionales, promovieron un fuerte activismo desde cada uno de sus ámbitos laborales. Se aprovechó así la apertura participativa que abría el gobierno cubano y se puso en la agenda pública el problema de las desigualdades laborales por orientación sexual, identidad de género y portar vih. La campaña por la inclusión en el artículo 2 de estas categorías tuvo en el activista Francisco Rodríguez, periodista del periódico oficialista Trabajadores, uno de los pilares en la constitución de este tema como un problema público.

Aseguran las autoras Araujo, Guzmán y Mauro (2000) que un ciclo ideal para construir una política pública, se inicia con la tematización y problematización de una experiencia por distintos actores que la conciben como inaceptable. En ese sentido, el propósito de la iniciativa, lanzada a través de internet para conectar a muchos otros activistas de los medios de comunicación, era que cada trabajador o trabajadora LGBTI se convirtiera en activista dentro de su centro de trabajo y promoviera el debate a favor de incluir estos tres elementos como categorías de desigualdades en el trabajo.

Para entender cómo este problema se posicionó en la agenda pública de Cuba hay que tener presente el análisis apoyado en el referente que constituyó el caso de la violencia doméstica en Chile, sobre el cual reflexionan estas autoras. Refieren Araujo et al., (2000, p. 1) que «los problemas públicos no existen por sí mismos como meros fenómenos objetivos, sino que son construidos por actores que se mueven en distintos escenarios, intercambiando y confrontando discursos que se sustentan en marcos interpretativos variados». Esto no quiere decir que las desigualdades en el trabajo para los LGBTI sean inventadas como si no existieran en realidad. Podría decirse que lo que sí se construye es el tema como un problema público que adquiere visibilización política.

Si se piensa en el caso cubano se puede comprender que las desigualdades a partir de la sexualidad, el género y el estatus vih no normativos se configuró como un problema público desde los propios centros de trabajo. En la asamblea sindical, donde se discutió el Anteproyecto de Ley del Código de Trabajo, el debate fue fructífero por los conflictos que desató y también los acuerdos. Tres activistas gais expusimos las razones por las cuales considerábamos necesario incluir la orientación sexual, la identidad de género y portar vih en el artículo 2 sobre derecho al trabajo. Allí se obtuvo un apoyo considerable de la mayoría de los asistentes y en el acta quedó registrada la petición junto a otras del resto de trabajadores que promovían cuestiones contractuales, salarios, garantías para acceder al estudio, sobre la maternidad. 
De acuerdo con Araujo et al., (2000), el ciclo para construir una política pública continúa, luego de esa problematización, con la incorporación en las agendas institucionales del problema polemizado. A pesar de ello, todos los problemas públicos no llegan a formar parte de las agendas institucionales. Ése es otro elemento que revela el carácter construido de los problemas como asuntos públicos. Para el caso de Cuba no se podría precisar en cuántas asambleas sindicales sucedió lo mismo. Sin embargo, el hecho de que el parlamento cubano, reacio a tocar los temas de las diversidades sexuales y de género, haya discutido el problema de las desigualdades laborales para las poblaciones LGBTI hace pensar que el caso no fue aislado y que la campaña por la inclusión en el artículo 2 de la orientación sexual, la identidad de género y portar vih logró su principal propósito: las desigualdades en trabajo a partir del género, la sexualidad y el estatus vih no normativos se construyó como un problema público que alcanzó entrar a la agenda pública del país.

\section{DISCURSOS SEXOGENÉRICOS DE DIPUTADAS Y DIPUTADOS: EL CHOQUE}

En los debates parlamentarios sobre el Anteproyecto del Código de Trabajo uno de los temas que centraron las discusiones fue la construcción del artículo 2 sobre el derecho al trabajo. En esta apartado la pretensión del movimiento LGBTI cubano era la inclusión en el mismo de las categorías orientación sexual, identidad de género y portar vih. Esta iniciativa no hubiera sido posible sin la presión en la propia Asamblea Nacional del Poder Popular de la diputada Mariela Castro, líder autotitulada del colectivo sexogénero diverso en la isla. La posición estratégica, por primera vez en el parlamento de la hija del presidente de la república, permitió que estas demandas del movimiento no quedaran sin atenciones por la máxima entidad legislativa del país.

Sin embargo, todos sabían que nuestras propuestas debían lidiar con los prejuicios heteronormativos y machistas que usualmente han acompañado la ideología socialista cubana, en particular las concepciones sobre sexualidad al interior del Partido Comunista de Cuba. Pero, ¿por qué la sexualidad ha estado cargada de tanta significación y puede entenderse a la vez como un terreno de conflictos? En la propuesta teórica de la socióloga ecuatoriana Argüello (2013) se pueden ubicar algunas pistas sobre las condicionantes que participan en el proceso de politización de la sexualidad. En este sentido, puede comprenderse que se trata de un escenario de disputas donde los actores poseen nociones construidas de lo que es correcto e incorrecto no solo en el ámbito de la sexualidad sino también del género. Por ello, el choque entre las propuestas del colectivo LGBTI y los diputados cubanos fue un marco oportuno para comprender los discursos que en materia de sexualidades y género rigen las decisiones políticas en el país. Como bien asegura esta autora, «las sexualidades constituyen un campo de disputa, un ámbito de politicidad» (Argüello, 2013, p. 183). Así lo que se construye en torno a normas y valores tiene un fuerte componente político de un lado y del otro.

En el análisis de los debates televisados de las sesiones parlamentarias para la aprobación del Código de Trabajo se pueden apreciar discursos que establecen límites a las formas de relacionamiento a partir de la sexualidad. Los asambleístas aceptarían las uniones civiles entre homosexuales pero no la adopción de niños. También son críticos respecto a la manifestación pública de las identidades transgénero. Algunos diputados entienden que tanto la orientación 
sexual como la identidad de género son cuestiones similares que no requieren tanta atención por separado. Para muchos de ellos, en cualquier caso se trataría del mismo «tipo» de persona comúnmente conocida en Cuba como «maricón», aunque el puritanismo parlamentario impide que se enuncie de esta forma.

La diputada Mariela Castro explicó en el debate las diferencias que encarnan estas categorías identitarias y los sujetos variables que pueden construirse a partir de las mismas. Algunos diputados apoyaron el discurso de la directora del CENESEX como la pastora presbiteriana Miriam Ofelia Ortega, el pastor episcopal Pablo Odén Marichal y el escritor y diputado Miguel Barnet, incluso Miguel Díaz-Canel, primer vicepresidente de los Consejos de Estado y de Ministros, llamó a tomar en cuenta la necesidad de justicia hacia las personas homosexuales, transgéneros y seropositivas.

A pesar de ello, para un auditorio deshabituado a explicaciones complejas sobre las identidades sexogenéricas, estas nociones parecieron demasiado abyectas y ambiguas. Argumentaron en contra por supuestas razones de técnica jurídica el diputado Homero Acosta, secretario del Consejo de Estado, y José Luis Toledo Santander, presidente de la Comisión de Asuntos Constitucionales y Jurídicos de la Asamblea Nacional. Se decidió resolver la discusión en la comisión de estilo, que finalmente estaría encargada de redactar la ley. Así, vemos como la construcción de las desigualdades laborales como problema público quedó disminuido a una simple confusión lingüística o jurídica que debía ser resuelta en términos de estilo, pero obviamente no en dimensiones políticas.

El resultado ya lo anuncié con anterioridad. La orientación sexual como protección especial para el derecho al trabajo solo quedó incluida en el Código de Trabajo. Con ello, esta ley se presenta como la primera victoria en materia jurídica en beneficio para una parte del movimiento LGBTI cubano. Una de las matrices discursivas más frecuentes para sustentar este logro por parte de la mayoría de los diputados y las diputadas argumentaba que si queremos construir una sociedad socialista cada vez más igualitaria e inclusiva no pueden seguir dejándose fuera del proyecto a las poblaciones LGBTI.

Mariela Castro afirmó en una entrevista sobre este asunto: «Cuando la sociedad excluye, simplemente pierde el concurso de las personas y, a la vez, ellas pierden oportunidades. Hay fragmentación, segregación; nada más parecido a las políticas neoliberales que solo les interesa privilegiar a determinados grupos. Nosotros inconscientemente no podemos reproducir esos mecanismos, porque lo que se quiere es el bienestar colectivo con la participación de todos», (Rodríguez, 2015). Pero a pesar de este discurso socialista e igualitarista, las propuestas identidad de género y portar vih fueron excluidas y con ello las personas transgénero y viviendo con vih quedaron expuestas a desigualdades y arbitrariedades en el ámbito laboral. También este hecho hizo que las disparidades al interior del colectivo LGBTI, un grupo de por sí diverso y con conflictos internos, se profundizaran aún más.

¿Por qué resulta complicado entender a los cuerpos transgéneros o marcados por el estigma del vih? La interpretación que realiza Butler (1997) del continuo entre sexo, género, prácticas sexuales y deseo aporta algunas explicaciones para entender este asunto; también los análisis de Foucault $(1992,1995)$ constituyen referentes cuando se habla de cuerpos «enfermos». Butler (1997) entiende que este continuo se ha establecido como válido y normativo para reforzar la 
estructura de la heterosexualidad obligatoria a través de elementos codificables como los géneros inteligibles, que «son aquellos que instituyen y mantienen de alguna manera las relaciones de coherencia y contigüidad entre sexo, género, práctica sexual y deseo», (Butler, 1997, p. 17). En el imaginario heterosexual/cisgénero se espera que todos estos aspectos estén armónicamente dispuestos y tengan un continuo coherente. Entonces, es posible pensar que los sujetos que rompen esa unidad continua y coherente serían sancionados socialmente, como en el caso de los LGBTI. En las personas transgénero, sus desórdenes del continuo sexo/género/ deseo y sus indefiniciones sexogenéricas hacen que sean vistas como peligrosas por el cuestionamiento a lo supuesta naturalidad del sexo, el género y el deseo.

No obstante, los cuerpos marcados por el estigma del vih viven de manera distinta esta represión social que se estructura como desigualdades. Al ser el vih adquirido mayormente a través de relaciones sexuales, se considera que las ideas de perversidad, promiscuidad y sexo por placer son reforzadas en las personas que viven con vih. Habría que recordar a Foucault $(1992,1995)$ y sus reflexiones sobre la población como cuerpo que necesita ser higienizado. En nuestras sociedades, las personas seropositivas son vistas como enfermos que pueden contaminar al resto de la población y por tanto necesitan ser controlados. Este peligro es entendido más allá de la propagación física del virus para temer por la infección con las conductas sexuales no convencionales e «impuras» que llevarían, según este discurso, al contagio con el vih.

A partir de estas interpretaciones sobre los discursos de los diputados y diputadas se puede señalar que no solo las identidades sexuales y las identidades de género resultaron confusas, sino que a estas personas se les identifica usualmente como poblaciones vulnerables a contraer vih. O sea, en el imaginario del legislativo cubano lo más común es que una persona puede ser maricón, por ello vestirse de mujer y enfermar de sida. Cuando sabemos que sexo/género/ deseo no son necesariamente entendidos desde una única norma y que el riesgo a la infección con vih no proviene de la identidad sexogenérica por sí misma, sino que depende de las conductas de riesgo. A partir de ahí se puede comprender el porqué de los resultados inclusivos pero a la vez exclusivos del Código de Trabajo para el movimiento LGBTI. Los diputados y las diputadas nunca llegaron a entender estas realidades fuera de sus estereotipos, prejuicios y principios morales socialistas, a pesar del esfuerzo de Mariela Castro y otros diputados aliados.

\section{LA CIUDADANÍA Y EL DERECHO DE INCLUSIÓN/EXCLUSIÓN}

El Código de Trabajo de Cuba hizo miembros, por primera vez, del proyecto político cubano a lesbianas, gais y bisexuales. Esto resulta novedoso si se reconoce la historia de desigualdades, violencias y tensiones ocurridas entre el Estado y los grupos LGBTI, sobre todo a partir de la década de los sesenta. No obstante, la transformación del sistema legal en el ámbito del trabajo a favor de las diversidades sexuales y de género fue incompleta y reforzó algunas desigualdades. Lo hizo en el sentido que otorgó derechos a partir de la sexualidad a una parte del colectivo LGBTI y los negó a otra respecto al género y al vih.

¿Cómo es posible entender esta repartición de derechos de manera arbitraria? Argüello (2014) asegura que el sexo del Estado está constituido en el binario hombre/mujer, masculino/femenino. Pero también, sin duda, el Estado es construido a partir de una identidad 
sexo-genérica hegemónica: la heterosexualidad cisgénero. Entonces, desde ese poder se impone el derecho de quien merece la ciudadanía a partir de una perspectiva de ciudadanía pasiva. En el caso cubano, las personas transgénero y viviendo con vih fueron excluidas de la ciudadanía desde el poder. Es posible, de este modo, entender la ciudadanía pasiva como profunda lógica de exclusión y desigualdades, sobre todo las que se producen desde la sexualidad, el género y el estatus vih. Retomando a Vargas (2012) se entiende que la perspectiva hegemónica, imperante hoy sobre democracia y ciudadanía, ha obviado las consecuencias políticas, subjetivas y paradigmáticas de la diversidad y las consiguientes diferencias de acceso al poder y los recursos.

A pesar de esto, la iniciativa del movimiento LGBTI cubano redefinió las nociones de ciudadanía históricamente legitimadas por un Estado socialista heteronormativo de tradición y prácticas homofóbicas. Se apostó por la ciudadanía activa como mecanismo para construir derechos y se logró en una parte de los propósitos. En las propuestas de adición al Anteproyecto de Ley del Código de Trabajo se intentó crear, como dice Vargas (2012), permanentemente horizontes para la convivencia de lo diverso, en igualdad de condiciones y oportunidades, con derechos garantizados por el Estado y responsabilidades asumidas por las ciudadanías, específicamente en el ámbito laboral. Pero estas propuestas pugnaron con el discurso hegemónico de los diputados de la Asamblea Nacional opuestos a comprender la ciudadanía desde la diversidad. A pesar de las exclusiones de la identidad de género y portar vih de la ciudadanía laboral cubana, este caso resulta interesante analizarlo a partir de lo que sí se logró por el colectivo LGBTI. Entonces, podemos pensar que lo sucedido en Cuba también es analizable desde la ciudadanía activa por el papel que jugaron los actores del movimiento LGBTI cubano para que se pusiera en agenda pública el tema de las desigualdades en el trabajo. Y a pesar de que en esa disputa entre el Estado y el colectivo LGBTI solo fueron aceptadas una parte de las demandas, la búsqueda por ampliar las dimensiones ciudadanas obligó a pensar por primera vez en nuevas formas de ciudadanía e inclusión y nuevas representaciones plurales y diversas en la Asamblea Nacional del Poder Popular. Como bien asegura Vargas (2012), los contenidos de la dimensión sexual de la ciudadanía han sido un aporte significativo de los movimientos feministas y de diversidad sexual, al posicionar el reconocimiento del cuerpo como portador de derechos, «cargado de ciudadanía» y por lo tanto sujeto político, sujeto de conocimiento y libertad de decisión.

Para el colectivo LGBTI cubano «la ciudadanía se ha de concebir como una actividad continua y un bien en sí, y no como un compromiso momentáneo (o una revolución socialista) con la vista puesta en un objetivo final o en un arreglo social» (Dietz, 2001, p. 121). De este modo, la experiencia de la aprobación del Código de Trabajo servirá para establecer nuevas disputas en un futuro cuando finalmente se someta a discusión el nuevo Código de Familia y tal vez la misma Constitución de la República.

\section{CONCLUSIONES}

Aunque en la construcción del artículo 2 del Código de Trabajo de Cuba se incluyó a la orientación sexual como categoría por las cual las personas no pueden ser sujetos de desigualdades en los espacios laborales, los discursos sexogenéricos de los diputados y las diputadas del parlamento cubano excluyeron la identidad de género y portar vih de la redacción final de la 
norma. Con esta exclusión de la ley laboral las personas transgénero y viviendo con vih no solo se exponen a la precariedad y las arbitrariedades de empleadores y compañeros de trabajo, sino también se profundizan las desigualdades al interior de un colectivo tan diverso como el LGBTI. A la vez, a ambas poblaciones se les prohíbe el privilegio de ser ciudadanos a través del Código de Trabajo. De este modo, son privados de ejercer el derecho al trabajo en condiciones igualitarias para todos y de pertenecer y participar en la construcción del proyecto político y social cubano como ciudadanos de derechos.

No obstante, mediante la inclusión de la orientación sexual en el Código de Trabajo de Cuba se reparó, tal vez por primera ocasión y en una ley, el daño por las invisibilizaciones y exclusiones que históricamente han vivido las lesbianas, gais y bisexuales cubanos. Esto resulta novedoso si se reconoce la predisposición discriminatoria hacia las poblaciones LGBTI que tradicionalmente ha mantenido el Estado cubano desde la instauración del modelo socialista en 1959. Y a pesar de este logro histórico del movimiento de las diversidades sexuales y de género en Cuba, en el imaginario político cubano las categorías orientación sexual e identidad de género se entienden de manera ambigua e incluso se refuerzan las estigmatizaciones cuando se identifican a homosexuales, bisexuales y transgéneros como potenciales enfermos de sida. Esta propia idea de que las poblaciones LGBTI nos identificáramos con el vih constituyó una acción estratégica por aunar fuerzas en una misma lucha, por los mismos propósitos a favor de una ciudadanía sexual plena.

Sin duda, esta experiencia de participación política y activismo LGBTI en torno a la aprobación del Código de Trabajo puede constituir una referencia para las venideras contiendas por el reconocimiento de derechos, la redistribución material y simbólica, y la representación en el Estado cubano de las poblaciones sexogénero diversas. Tal vez para que de una vez se someta a discusión el nuevo Código de Familia que pretende reconocer las uniones civiles entre parejas LGBTI, o para que la Constitución de la República (1976) se ajuste a los nuevos tiempos que vive el país.

\section{NOTA}

1 Este artículo fue un ensayo previo del autor escrito para la Flacso, en donde utiliza la primera persona («yo escribo», «aprovechamos», etc.) para demostrar el apoyo, la pertenencia y la militancia del autor con el movimiento LGBTI. Los editores de la Revista Economía, por evidentes cuestiones de estilo, han cambiado esta pronominalización por la tercera persona; a la vez que han respetado el uso lexicalizado de la sigla VIH, que el autor la usa en minúsculas.

\section{REFERENCIAS}

Araujo, K., Guzmán, V. y Mauro, A. (abril, 200o). El surgimiento de la violencia doméstica como problema público y objeto de políticas. Revista de la CEPAL, (70), 133-145.

Argüello, S. (2013). El proceso de politización de la sexualidad: identificaciones y marcos de sentido de la acción colectiva. Revista Mexicana de Sociología, 75(2), 173-200.

Argüello, S. (2014). ¿Tiene sexo el Estado? Imbricaciones entre las luchas políticas transgénero y el Estado en Ecuador, 2002-2013. En M. Estrada y A. Agudo (Eds.), Formas reales de dominación del 
Estado. Perspectivas interdisciplinarias del poder y la política (pp. 111-149). México DF, México: El Colegio de México.

Asamblea Nacional del Poder Popular. (2013). Anteproyecto de Ley del Código de Trabajo de Cuba. Recuperado de http://www.trabajadores.cu/wpcontent/uploads/2013/oz/Anteproyecto-Ley-C odigo-Trabajo-Cuba-2013.pdf.

Asamblea Nacional del Poder Popular. (2014). Código de Trabajo de Cuba. Recuperado de http://www. cubadebate. cu/wp content/uploads/2014/o6/codigo-del-trabajo-de-la-republica-de-cuba.pdf

Butler, J. (1997). Sujetos de sexo/género/deseo. Feminaria, 10(19), 1-20.

Butler, J. (1998). El género en disputa. El feminismo y la subversión de la identidad. México DF, México: Paidós.

Cabral, M. y Viturro, P. (2006). (Trans)Sexual citizenship in contemporary Argentina. En P. Currah, R. Juang y Sh. Price (Eds.), Transgender Rights. Minneapolis, UsA: University of Minnesota Press.

Camacho, M. (2007). Diversidades sexuales y de género: exclusión social e inserción laboral en Quito. Quito, Ecuador: UASB-Ecuador.

Dietz, M. (marzo, 2001). El contexto es lo que cuenta: feminismo y teorías de la ciudadanía. Debate Feminista, 1(1), 3-32.

Foucault, M. (1992). Genealogía del racismo. Madrid, España: La Piqueta.

Foucault, M. (1995). Historia de la sexualidad. Tomo I. La voluntad de saber. México DF, México: Siglo xxI.

Gala, Á. et al. (mayo, 2007). Dinámica de adquisición del viH en su dimensión social, ambiental y cultural. Revista Cubana de Medicina Tropical, 59(2), 90-97.

Molyneux, M. (2008). Justicia de género, ciudadanía y diferencia en América Latina. En M. Prieto (Ed.), Mujeres y escenarios ciudadanos (pp. 22-56). Quito, Ecuador: FLAcso-Ecuador.

Rich, A. (1999). Heterosexualidad obligatoria y existencia lesbiana. Duoda Revista d'Estudis Feministes, (10), 15-45.

Rodríguez, F. (17 de mayo del 2015). La sociedad que excluye pierde oportunidades. Trabajadores. Recuperado de http://www.trabajadores.cu/20150503/la-sociedad-que-excluye-pierde-oportun idades/

Romero, C. (2003). De diferencias, jerarquizaciones excluyentes y materialidades de lo cultural. Una aproximación a la precariedad desde el feminismo y la teoría queer. Cuadernos de Relaciones Laborales, 21(1), 33-66.

Serano, J. (2007). Whipping girl: A transsexual woman on sexism and the scapegoating of femininity. Berkeley, usa: Seal Press.

Vargas, V. (2012). Democracia con tiempos de beligerancia: los retos en la construcción de la ciudadanía de las mujeres en el siglo Xxi. Ponencia presentada en el II Foro Hemisférico. Liderazgo de las mujeres para la democracia de ciudadanía. Santo Domingo, República Dominicana. 
